\title{
Histopathological Aspects in Oral Squamous Cell Carcinoma
}

\author{
Bunget $\mathrm{AM}^{1}$, Dascălu $\mathrm{IT}^{2 *}$, Coleș $\mathrm{E}^{3}$, Țîrcă $\mathrm{T}^{3}$, Stan $\mathrm{M}^{4}$, Găman $\mathrm{S}^{5}$ \\ and Nicola $\mathrm{AG}^{\mathbb{1}}$ \\ ${ }^{1}$ Department of Oro-Dental Prevention, Faculty of Dental Medicine, University of
} Medicine and Pharmacy of Craiova, Romania

${ }^{2}$ Department of Orthodontics, Faculty of Dental Medicine, University of Medicine and Pharmacy of Craiova, Romania ${ }^{3}$ Department of Dental Morphology and Semiology System, Faculty of Dental Medicine, University of Medicine and Pharmacy of Craiova, Romania

${ }^{4}$ Department of Dental Materials, Faculty of Dental Medicine, University of Medicine and Pharmacy of Craiova, Romania

${ }^{5}$ Department of Prosthetic Dentistry, Faculty of Dental Medicine, University of Medicine and Pharmacy of Craiova, Romania

*Corresponding author: Ionela Teodora Dascălu, Department of Orthodontics, Faculty of Dental Medicine, University of Medicine and Pharmacy of Craiova, Romania, Tel: 0724418366; Email: marceldascalu@yahoo.com

\section{Abstract}

Oral squamous cell carcinoma is a malignant neoplasm of stratified squamous epithelium, with the highest capacity of spread. The aim of the study was to identify and discriminate the various squamous cell lesions based on the differences in their histopathology.

143 patients with oral tumors were reviewed between 2008-2012 in Oral and Maxillofacial Surgery Clinic of the Emergency County Hospital of Craiova. We made a clinicostatistical study, and histopathological analyses for each tumor. We found 125 malignant tumors, including 115 squamous cell carcinoma.

By TNM staging, we found 85 patients $(73,91 \%)$ having III or IV stage tumors, 28 patients $(22,60 \%)$ with stage II and only 2 patients $(1,73 \%)$ with „in situ” carcinoma.

For a final diagnosis of oral squamous cell carcinoma, it is compulsory to make a clinical examination and also a histopathological analysis.

Keywords: Histopathology; Squamous Cell Carcinoma; Neoplasm

\section{Introduction}

Oral cancer, one of the major diseases worldwide, represents the most common form of neoplasm of head and neck region. Squamous cell carcinoma represents $90 \%$ of oral malignant tumors [1].
The incidence of oral cancer is very different all over the world, depending on the country [2]. According to some studies, this neoplastic lesion is the most common location for cancer in some regions from the southeastern Asia [3], while in North America and European Union the incidence of oral cancer is lower [2] in the last years the incidence of oral cancer decreased in United States, this 


\section{Open Access Journal of Dental Sciences}

trend being attributed to the reduction of alcohol and smoking habits [4-6].

The main etiological and predisposing factors in oral carcinogenesis are alcohol consumption and tobacco smoking, especially the association of the two habits, and also the ultraviolet radiation, or human papilloma virus infection [7]. Squamous cell oral carcinoma is a malignant tumor, which derives from the stratified squamous cells of oral mucosa [8].

Histological aspects show the gradually development of oral carcinoma from simple, moderate or severe dysplasia, to in situ carcinoma and, finally, to invasive tumor. From histopathologic point of view there are many types of squamous cell carcinoma, ranging from indolent tumors to very aggressive tumors, with high invasive potential [9-11]. The tumors were histologically classified as: in situ, well-differentiated, moderately differentiated, and poorly differentiated.

Diagnosis is still the most important prognostic sign for oral squamous cell carcinoma. The progress risk for premalignant lesions can be evaluated by histopatologic analysis.

\section{Material and Methods}

Our study included a number of 143 patients aged between 1 and 82 years, with oral tumoral lesions, retrieved in the files of Clinic of Oral and Maxillofacial Surgery of the Clinical Emergency Hospital of Craiova, Romania, between 2008 and 2012 [12].

After a clinicostatistical study, we also made a histopathological study performed on samples stained with Hematoxylin-Eosin and trichromic Goldner-Szekely. Histopathological study was performed in the Anatomic Pathology Laboratory of the Emergency County Hospital of Craiova. The tumor fragments were immediately fixed in $10 \%$ neutral formalin solution for $48-72$ hours at laboratory temperature $\left(21-23^{\circ} \mathrm{C}\right)$ and processed by paraffin inclusion. This technique includes: dehydration, clarification, paraffin inclusion, sectioning, attaching the sections on slide, drying, staining, and storage. The histological sections were stained with HematoxylinEosin and Goldner-Szekely technique green light trichromic or Van Gieson.

Oral mucosa has squamous stratified epithelium without keratinization, with variable thickness. It has 3 layers from the depth to the surface: basal layer, polyhedric cells layer, superficial layer. Histological structure also contains a corium layer under the epithelium, which is very important to study, because it is often affected by malignant tumors.

\section{Results}

In order to have a correct diagnosis for squamous cell oral carcinoma it is compulsory to realize histopathological analysis, to assess cell proliferation and maturation abnormalities, cellular and cytoplasmic atypia, and alteration of surface epithelium or deep tissues cytoarchitection.

In our study we made two classifications of oral carcinomas, one by TNM staging, and one by histopathological exam.

By TNM staging, we found 85 patients $(73,91 \%)$ having stage III or IV tumors, 28 patients $(22,60 \%)$ with stage II and only 2 patients $(1,73 \%)$ with „in situ" carcinoma.

After the microscopic study, from all the 143 tumors, we discriminated 18 benign tumors, and 125 malignant tumors. The main histopathological type of malignant tumors was squamous cell carcinoma ( $\mathrm{n}=115,92 \%)$. (Figure 1)

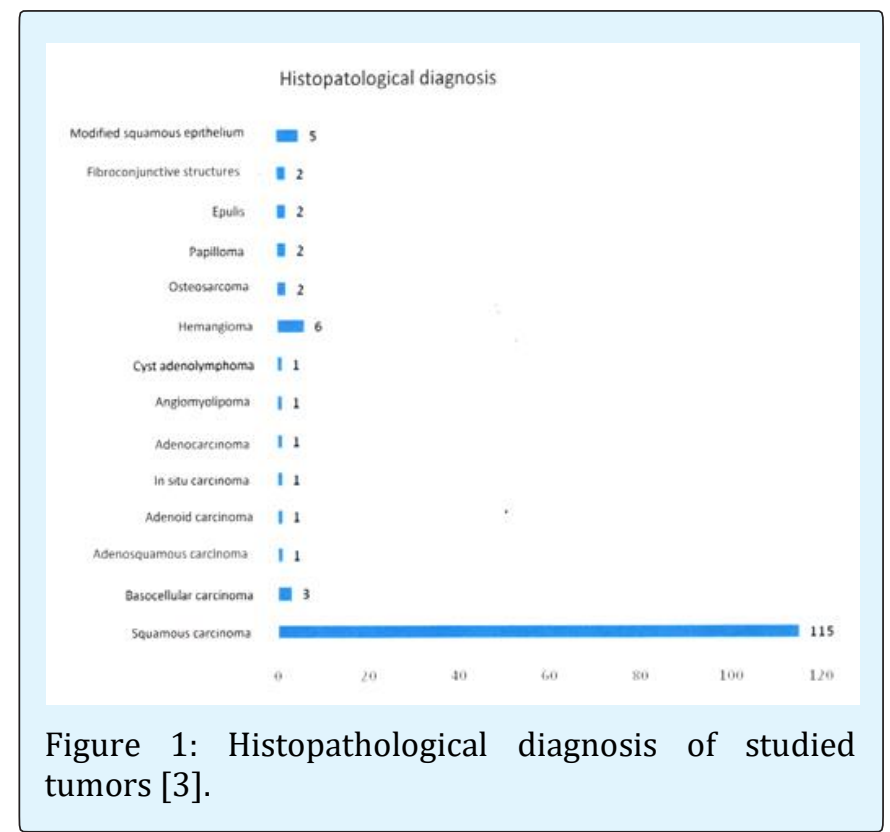

Histopathological aspects differentiated 3 types of squamous cell carcinoma: 61 cases of well differentiated squamous cell carcinoma (53, 03\%), 36 cases of moderated squamous cell carcinoma (31,30\%), and 18 cases of poorly differentiated squamous cell carcinoma $(15,65 \%)$. 


\section{Open Access Journal of Dental Sciences}

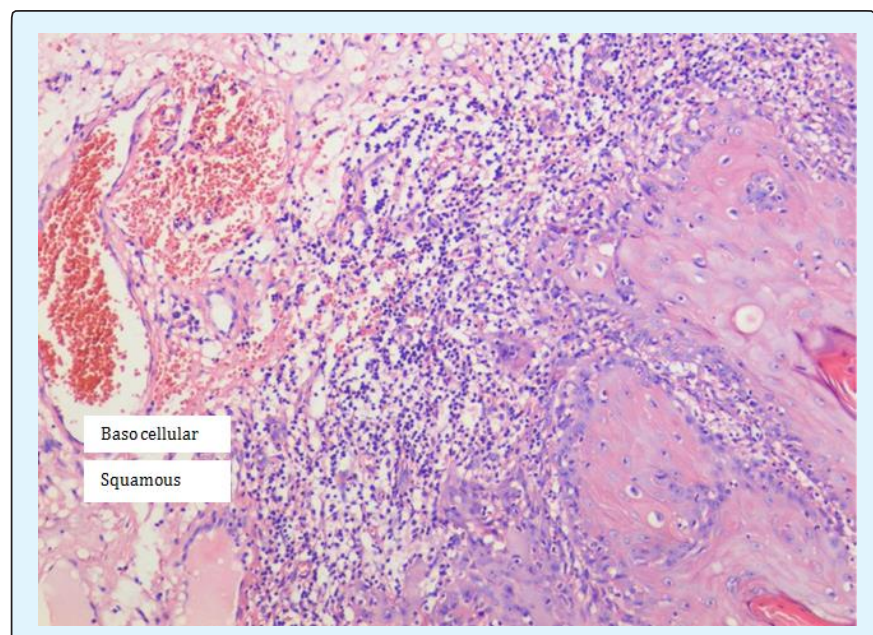

Figure 2: Invasion area of a well differentiated squamous cell carcinoma by the lingual mucosa in which it is noted infiltration of peritumoral stroma with immune cells" (Hematoxylin-Eosin staining [3].

Well differentiated squamous cell carcinomas contained well differentiated squamous cells, arranged as islands with different shapes and sizes, with keratinous pearls inside, determined by a process of "neoplastic maturation". Inside the keratinous pearls, cells were acidophil with pyknotic nuclei and karyolysis, while the rest of the cells had nuclei of different shapes and sizes, bigger than normal epithelium's nuclei. Many cells had polyedral aspects with intercellular spines (Figure 2).

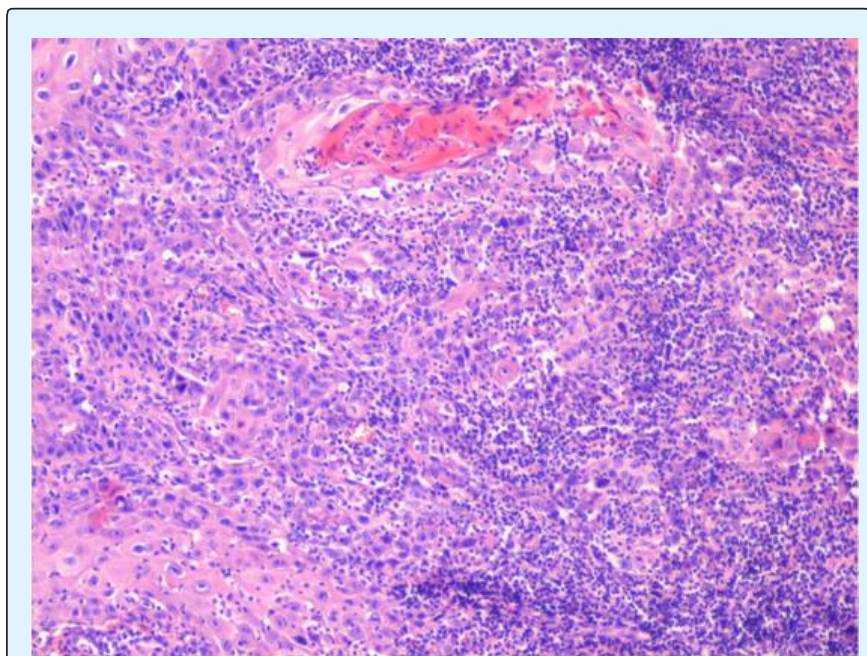

Figure 3: Microscopic aspects in a moderately differentiated lip carcinoma with squamous cells stroma infiltrated with immune cells (HematoxylinEosin staining) [3].
Moderately differentiated squamous cell carcinomas were organized in islands of neoplastic atypical epithelial cells, oval-shaped, oblong, round which infiltrated the tumoral stroma. At the periphery, carcinoma islands were separated by fibrous stromal elements or inflammatory type cells. Nuclei of neoplastic cells had different shapes and sizes, most of them hypochromic with large nucleoli. Tumor cells appeared as atypical cells diffusely scattered in the stroma of oral, lingual or labial mucosa, with rare intercellular bridges. Often tumor cells had large, deformed nuclei, hyperchrome or hypochromic, with pinholes and buddings, and multiple atypical mitosis (Figure 3).

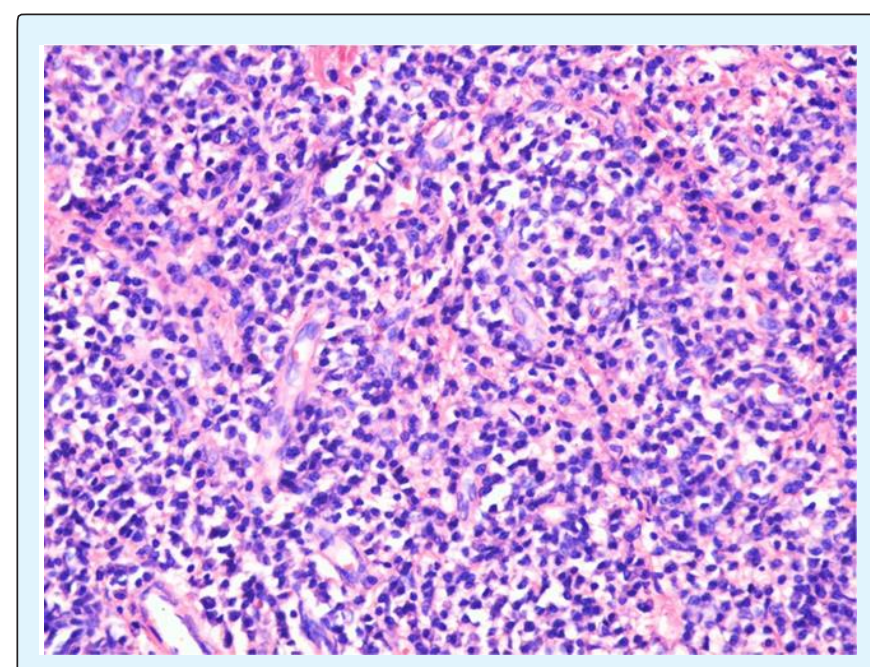

Figure 4: Poorly differentiated carcinoma of anterior pillar of amygdale.

Stroma rich in inflammatory cells and angiogenesis vessels (Hematoxylin-Eosin staining) [3]

Poorly differentiated squamous cell carcinomas were designed as cellula cords, islands or epithelioid-like cells of various shapes and sizes, with a different design from the normal epithelium. The various aspects of cancer cells means the malignant tumors are heterogeneous entities, multicellular, containing multiple cell lines whose interactions with each other and with the extracellular matrix through paracrine secreted soluble molecules are dynamic and promote cell proliferation, movement and differentiation of neoplasia (Figure 4).

Tumoral stroma results from the conversion of covering epithelium corium into stroma with particular features, as an adaption reaction to the tumoral invasion. Due to its vascular density, it has nutritional and supportive role for tumoral cells. 


\section{Open Access Journal of Dental Sciences}

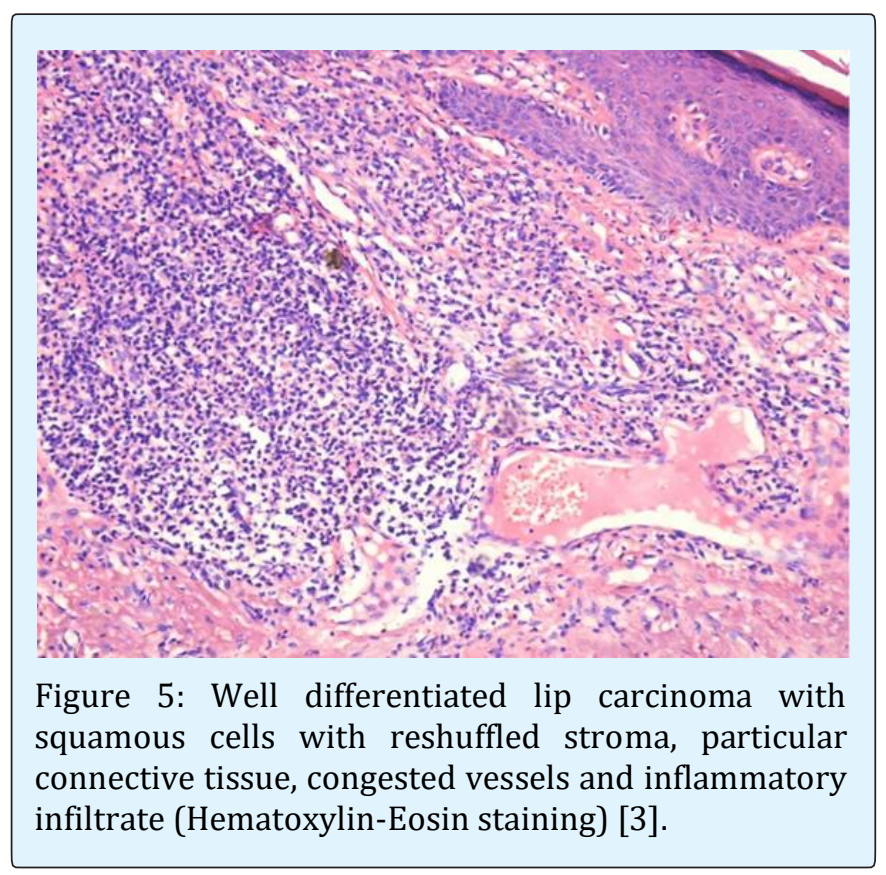

Immediate after the rupture of basal membrane, and the invasion of cancer cells into the underlying connective tissue, it shows up an inflammatory reaction, leading to the formation of a particular granulation tissue, which matures into tumoral stroma (Figure 5). In this tumoral stroma, under the induction of inflammatory and angiogenesis factors, will form a rich vascular network that will ensure the proliferation of the tumor (Figure 6).

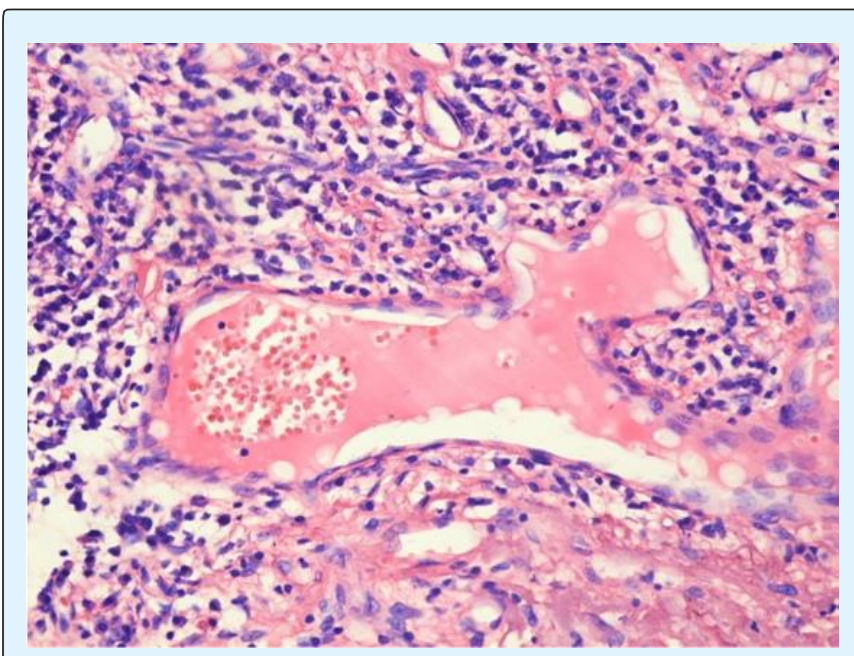

Figure 6: Well differentiated squamous cell lip carcinoma Tumoral stroma with young tissue, associated with vascular congestion (HematoxylinEosin staining) [3].

\section{Discussion}

Nowadays it is widely accepted the idea that oral cancer development is a multifactorial process involving many genetic features which alter the normal function of oncogenes and tumoral suppressive genes. Oral cancer represents $48 \%$ from all malignant tumors of head and neck, and $90 \%$ of them are squamous cell carcinomas.

The features of oral squamous cell carcinomas are different from the carcinomas located in other anatomical areas [13].

Most of the studies show a high incidence of squamous cell carcinoma in oral cavity, with a percentage of $80-90 \%$ of all oral cancers [14-16]. Fábio Ramôa Pires found in his study that one third of all oral malignant tumors were not squamous cell carcinomas [7].

The incidence of OSCC increases with age, with the most of oral squamous cell carcinoma occurring in patients after 40 years old [8]. Histopatological analysis is compulsory for diagnosis confirmation. Many wrong diagnosis of histopathological stages of SCC are caused by unrepresentative biopsy samples or by the difficulty of establishing a diagnosis based on histopathological features with routine hematoxylin-eosin staining [17]. Biopsy and histopathological exam, associated with other investigations, helps in final diagnosis of oral carcinomas [18].

Histologically, the lesion passes through various phases from initial cell injury until the ultimate formation of a cancer $[19,20]$. Many authors consider that oral squamous cell carcinomas are often preceded by a visible precancerous lesion, named dysplasia. Considering that malignant evolution of dysplasia occurs in many years, it is possible to prevent the oral cancer potential development.

Precancerous lesions of oral cavity are: leukoplakia, eritroplakia, and eritroleucoplakia. The carcinogenesis is considered to be initiated by a precancerous lesion such as leukoplakia, erythroplakia and mixed, but not all preneoplastic damage or potentially malignant lesions may develop of malignant neoplasms [21].

Many authors used various histologic grading systems to describe and classify squamous cell carcinomas. Histological exam studied the relationship of the neoplasm to the surrounding host tissue, morphological parameters structure, tendency to keratinization, nuclear aberrations, number of mitosis, and stage of invasion, 


\section{Open Access Journal of Dental Sciences}

vascular invasion and lymphoplasmocytic infiltration [2226].

Despite the direct access to oral cavity examination, squamous cell carcinomas are still detected in late stages, thus the survival rate is still low.

Using molecular biology technics for precancerous and cancerous oral lesions diagnose may improve the detection of damages which are invisible to macroscopic and to routine staining microscopically examination. The prognosis of oral squamous cell carcinomas is determined by a wide range of tumor features: histopathologic type, invasive front grade, lymphovascular invasion, tumor size and site [17]. Angiogenesis is one of the most important factors in tumor progression and metastasizing potential of solid tumors [1]. A series of studies demonstrated the protective role of inflammatory cells in the development of tumors [17].

In our study, premalignant and malignant lesions stroma was often strongly modified and infiltrated with inflammatory cells like: macrophages, lymphocytes, plasmacytes, mast cells. The most significantly aspects in tumoral stroma were vascular modifications, like vessels congestion and angiogenesis.

\section{Conclusions}

Despite the high incidence of squamous cell carcinomas in oral cavity, the metastasis, recurrence and survival of these tumors are still not well determined. For a final diagnosis of oral squamous cell carcinoma, it is compulsory to make a clinical examination and also a histopathological analysis.

\section{Acknowledgements}

All authors have equal contribution to the manuscript.

\section{References}

1. Stîngă AC, Mărgăritescu 0 , Stîngă AS, Pirici D, Ciurea R (2011) VEGFR1 and VEGFR2 immunohistochemical expression in oral squamous cell carcinoma: a morphometric study. Rom J Morphol Embryol 52(4): 1269-1275.

2. Santarelli A, Lo Russo L, Bambini F, Campisi G, Lo Muzio L (2009) New perspectives in medical approach to therapy of head and neck squamous cell carcinoma. Minerva Stomatol 58(9): 445-452.
3. John GB (2003) The histology of oral cancer. In: Shah JP, Johnson NW, Batsakis JG, (Edr.), Oral cancer, London, Martin Duntiz, pp: 129-164.

4. Canto MT, Devesa SS (2002) Oral cavity and pharynx cancer incidence rates in the United States, 19751998. Oral Oncol 38(6): 610-617.

5. Polednak AP (2009) Trends in incidence rates of tobacco-related cancer, selected areas, SEER Program, United States, 1992- 2004. Prev Chronic Dis 6(1): A16.

6. Fronie A, Bunget A, Afrem E, Preoţescu LL, Puşcu DC (2013) Squamous cell carcinoma of the oral cavity: clinical and pathological aspects, Rom J Morphol Embryol 54(2): 343-348.

7. Pires FR, Ramos AB, Oliveira JB, Tavares AS, Luz PS, et al. (2013) Oral squamous cell carcinoma: clinicopathological features from 346 cases from a single Oral Pathology service during an 8-year period. J Appl Oral Sci 21(5): 460-467.

8. Tumuluri V, Thomas GA, Fraser IS (2002) Analysis of the Ki-67 antigen at the invasive tumour front of human oral squamous cell carcinoma. J Oral Pathol Med 31(10): 598-604.

9. Lohmann CM, Solomon AR (2001) "Clinicopathologic variants of cutaneous squamous cell carcinoma," Advances in Anatomic Pathology 8(1): 27-36.

10. Cassarino DS, DeRienzo DP, Barr RJ (2006) "Cutaneous squamous cell carcinoma: a comprehensive clinicopathologic classification-part two. J Cutan Pathol. 33(4): 261-279.

11. Cassarino DS, DeRienzo DP, Barr RJ (2006) Cutaneous squamous cell carcinoma: a comprehensive clinicopathologic classification-part one. J Cutan Pathol 33(3): 191-206.

12. Bunget A, Thesis MD, Angiogenesis and lymphangiogenesis in oral squamous carcinomas a histopathological and immunohistochemical study.

13. Jasmin Singh (2014) Histopathology of oral squamous cell carcinoma - a review 1(4): 141-144.

14. Johnson NW, Jayasekara P, Amarasinghe AA (2011) Squamous cell carcinoma and precursor lesions of the oral cavity: epidemiology and etiology. Periodontol 57(1): 19-37. 


\section{Open Access Journal of Dental Sciences}

15. Moore SR, Johnson NW, Pierce AM, Wilson DF (2000) The epidemiology of mouth cancer: A review of global incidence. Oral Dis 6(2): 65-74.

16. Pereira MC, Oliveira DT, Landman G, Kowalski LP (2007) Histologic Subtypes of Oral Squamous Cell Carcinoma: Prognostic Relevance. J Can Dent Assoc 73(4): 339-344.

17. Gherghina FL, Camen A, Munteanu MA, Mărgăritescu C, Şarlă CG (2016) Parotid sclerosing mucoepidermoid carcinoma: a case report and immunohistochemical study, Rom J Morphol Embryol 57(3): 1107-1116.

18. Hanahan D, Weinberg RA (2000) The hallmarks of cancer. Cell 100(1): 57-70.

19. César Rivera, Bernardo Venegas (2014) Histological and molecular aspects of oral squamous cell carcinoma (Review). Oncol Lett 8(1): 7-11.

20. Neville BW, Day TA (2002) Oral cancer and precancerous lesions. CA Cancer J Clin 52(4): 195215.

21. Jakobsson PA, Eneroth CM, Killander D, Moberger G, Martensson B (1973) Histological classification and grading of malignancy in the carcinoma of the larynx. Acta Radiol Ther Phys Biol 12(1): 1-8.

22. Bunget A, Fronie A, Afrem E, Puscu DC, Manolea H (2013) Microscopic aspects of angiogenesis and lymphangiogenesis in oral squamous cell carcinoma. Rom J Morphol Embryol 54(3): 623-627.

23. Munteanu C, Pirici D, Stepan AE, Camen A, Margaritescu C (2016) Maxillary calcifying epithelial odontogenic tumor with sinus and buccal vestibule extension: a case report and immunohistochemical study. V Diagn Pathol 11(1): 134.

24. Fisher HR (1995) Grading of biopsies of laryngeal carcinomas by multiple criteria. Can J Otolaryngol 4(5): 881-884

25. Jakobsson PA, Eneroth CM, Killander D, Moberger G, Martensson Bc (1973) Histological classification and grading of malignancy in the carcinoma of the larynx. Acta Radiol Ther Phys Biol 12(1): 1-8.

26. Sapp JP, Eversole LR, Wysocki GP (2004) Contemporary Oral and Maxillofacial Pathology Chapter 6: Epithelial Disorders. 2 ${ }^{\text {nd }}(E d n$.$) ,$ Mosby Year Book Inc, Maryland Heights, pp: 184-193. 